\title{
Evaluation of Bias in the Measurement of Condensable Particulate Matter with Method 202
}

Aerosol and Air Quality Research

\section{OPEN ACCESS}

Received: April 13, 2020

Revised: July 3, 2020

Accepted: July 31, 2020

${ }^{*}$ Corresponding Author:

chihweilin1981@gmail.com

\section{Publisher:}

Taiwan Association for Aerosol Research

ISSN: $1680-8584$ print

ISSN: 2071-1409 online

(c) Copyright: The Author(s) This is an open access article distributed under the terms of the Creative Commons Attribution License (CC BY 4.0), which permits unrestricted use, distribution, and reproduction in any medium, provided the original author and source are cited.

\section{Yu-Mei Huang ${ }^{1}$, Sheng-Hsiu Huang ${ }^{1}$, Chih-Wei Lin ${ }^{1 *}$, Hsi-Hsien Yang ${ }^{2}$, Chih-Chieh Chen ${ }^{1}$}

${ }^{1}$ Institute of Environmental and Occupational Health Science, College of Public Health, National Taiwan University, Taipei 10055, Taiwan

${ }^{2}$ Department of Environmental Engineering and Management, Chaoyang University of Technology, Taichung 41349, Taiwan

\section{ABSTRACT}

The present study evaluated the positive and negative biases in measurements of condensable particulate matter (CPM) conducted according to U.S. EPA Method 202. To reduce the overestimation of $\mathrm{CPM}$, four factors were investigated: the $\mathrm{SO}_{2}$ absorption, condensate volume, oxygen content, and residence time. The underestimation was assessed by examining the weight loss related to the electrostatic charge of the evaporation beaker, vapor pressure of the particles, volume of the rinsing solvent, size of the evaporation beaker, and leakage between the filter paper and its holder. Additionally, we constructed a forced ventilation chamber to decrease the drying time of the sampled CPM's organic fraction. The results revealed that our homemade condensate-diverting impinger could neither eliminate nor reduce the artifacts produced by $\mathrm{SO}_{2}$, as the $\mathrm{SO}_{2}$ had already oxidized by the time it passed through the Graham condenser and interacted with water. Since the residence time, condensate volume, and oxygen content can all exacerbate the overestimation of CPM, field sampling should be performed as quickly as possible. Furthermore, the evaporation beaker should be electrostatically neutralized prior to its weighing. Nitrogen purging may reduce the mass of the particle fraction possessing high vapor pressure, as these substances are highly volatile. Also, we found that when we used a smaller beaker, less residual mass remained in it after transferring the CPM sample to the weighing tin. We measured a $4 \%$ loss in particles due to the gap between the filter paper and the filter paper holder provided by the original manufacturer; therefore, a gasket to minimize leakage is recommended. Finally, the organic fraction required only $1.5-2.5 \mathrm{~h}$ of drying time when it was placed in the forced ventilation chamber, and a sample recovery rate of $>98.5 \%$ was subsequently achieved. Although artifacts produced by $\mathrm{SO}_{2}$ are inevitable, the improvements we suggest can enhance the precision of $\mathrm{PM}_{2.5}$ measurements.

Keywords: Condensable particulate matter, $\mathrm{SO}_{2}$ artifact, Method 202, Stack sampling

\section{INTRODUCTION}

Particulate air pollutants can severely affect the environment, economy, and health (Ramanathan et al., 2007; Apte et al., 2015; Xie et al., 2016). They can travel across large areas and countries, leading to regional or global air pollution (Yang et al., 2008; Karthik et al., 2017). Particulate matter emitted from the stationary sources is one source of artificial particulate pollutants and has a high concentration and complex composition, making it necessary to attain an improved understanding of emission composition (Wang et al., 2016). Particulate matter can be divided into filterable particulate matter (FPM), which exists in the solid or liquid phase in stack flue gas, and condensable particulate matter (CPM), which exists in the gas/vapor phase in stack flue gas. As CPM leaves the stack, it cools down in the atmosphere and condenses to form solid or liquid particulate matter. 
Currently, almost all developed countries have established limits for FPM concentration and emission. However, the concentration of CPM is often higher than that of FPM for different stationary sources (Corio and Sherwell, 2000; Miller, 2015; Pei, 2015; Wang et al., 2018; Yang et al., 2018a; Zheng et al., 2018; Yang et al., 2019). For example, the concentrations of CPM are 1.03-2.87 times higher than that of FPM 2.5 for coal-fired power plants (Yang et al., 2014; Li et al., 2017; Yang et al., 2018b). It is found that CPM is composed mostly of inorganic matter (Corio and Sherwell, 2000) and water-soluble ions such as $\mathrm{SO}_{4}{ }^{2-}$ are main contributors of inorganic component (Qi et al., 2018; Wang et al., 2018; Yang et al., 2018b). Overall, data on the emission of CPM remains limited. Therefore, a thorough investigation of the emission characteristics and concentrations of CPM is urgently required. Stack exhaust temperature is the basis of theoretical definitions of CPM and FPM at the time of sampling, and is the key factor affecting CPM concentration (Yang et al., 2014). The CPM measurement method follows the principle of condensation, reducing the temperature by ice bath cooling or clean ambient air dilution. The cooling sampling method is a direct technique for sampling CPM; the process involves filtering flue gas with filter paper to remove FPM and then cooling the filtered gas to $20-30^{\circ} \mathrm{C}$. Once it falls within this temperature range, the gaseous CPM transforms into liquid or solid particles. The impinger and filter paper are then used to capture CPM. Nitrogen is used to purge the sampling system, mainly for removing $\mathrm{SO}_{2}$ that was likely produced during combustion.

Even though the measurement method for CPM was first promulgated in 1991 and some revisions were made later (U.S. EPA, 2016), its accuracy is often questioned because of high variation. For example, $\mathrm{SO}_{2}$ often interferes with sampling results, resulting in overestimation (Richards et al., 2005; Wang et al., 2020). The present study involved evaluating the biases and imprecision of the CPM measurement method and proposing measures to improve the overall method performance.

\section{METHODS}

In this study, an experimental system was set up to simulate CPM sampling and measurement in the laboratory for assessing positive and negative biases (Fig. 1). The testing parameters adopted are shown in Table $1 . \mathrm{SO}_{2}$ was generated using a standard gas cylinder at a concentration of $100 \mathrm{ppm}$, which falls in the range of most major stationary sources' $\mathrm{SO}_{2}$ emission standard. In addition, $\mathrm{SO}_{2}$ can be easily detected at this concentration. The experimental CPM sampling system used an impinger as specified in Method 202 (Method 202 System; Apex Instruments, Fuquay-Varina, NC, USA), with a sampling flow rate of $10.7 \mathrm{~L} \mathrm{~min}^{-1}$. In addition, a homemade condensate-diverting (CD) impinger was designed to replace the standard modified GreenburgSmith (GS) impinger as specified in Method 202 in order to minimize the contact time between $\mathrm{SO}_{2}$ and water. A funnel was added to the $\mathrm{CD}$ impinger to divert the condensate out of the impinger and to reduce the time of contact between $\mathrm{SO}_{2}$ and the condensate. $\mathrm{An} \mathrm{SO}_{2}$ detector (MultiRAE Lite; Honeywell International Inc., NJ, USA) was calibrated and used to directly measure $\mathrm{SO}_{2}$ concentration downstream of the GS impinger. The measurements were used to determine the water absorption curve for $\mathrm{SO}_{2}$. A known volume of water in the range of 100$300 \mathrm{~mL}$ was directly added into the GS impinger to simulate the effect of condensate volume on the artifact during sampling. For the evaluation of the $\mathrm{CD}$ impinger, water and $\mathrm{SO}_{2}$ was injected using an injection pump (KDS 200/200P Legacy; KD Scientific Inc., Holliston, MA, USA) into the Graham condenser while simultaneously sampling $\mathrm{SO}_{2}$. The water injection rate was $1.6 \mathrm{~mL} \mathrm{~min}^{-1}$, the total water volume injected was $100 \mathrm{~mL}$, and the sampling time was $60 \mathrm{~min}$, which is equivalent to the parameters of a stack with a water content of $21.3 \%$.

Air and high-purity nitrogen were used to assess the effects of purging time and oxygen concentration on the artifact at the time of purging. The wait time between the end of the sampling process and the beginning of nitrogen purging was determined. Two sets of experiments with a total operation time (residence time) of $3 \mathrm{~h}$ each were conducted to investigate the effect of wait time, one with a sampling time of $0.5 \mathrm{~h}$ and wait time of $2.5 \mathrm{~h}$ and the other with a sampling time of $3 \mathrm{~h}$. The Greenburg-Smith impinger was used to evaluate the recovery efficiency of different volumes of hexane. Glycerol and diethylhexyl sebacate (DEHS) were used to simulate organic and inorganic CPM, respectively. An atomizer (Collison Nebulizer; 


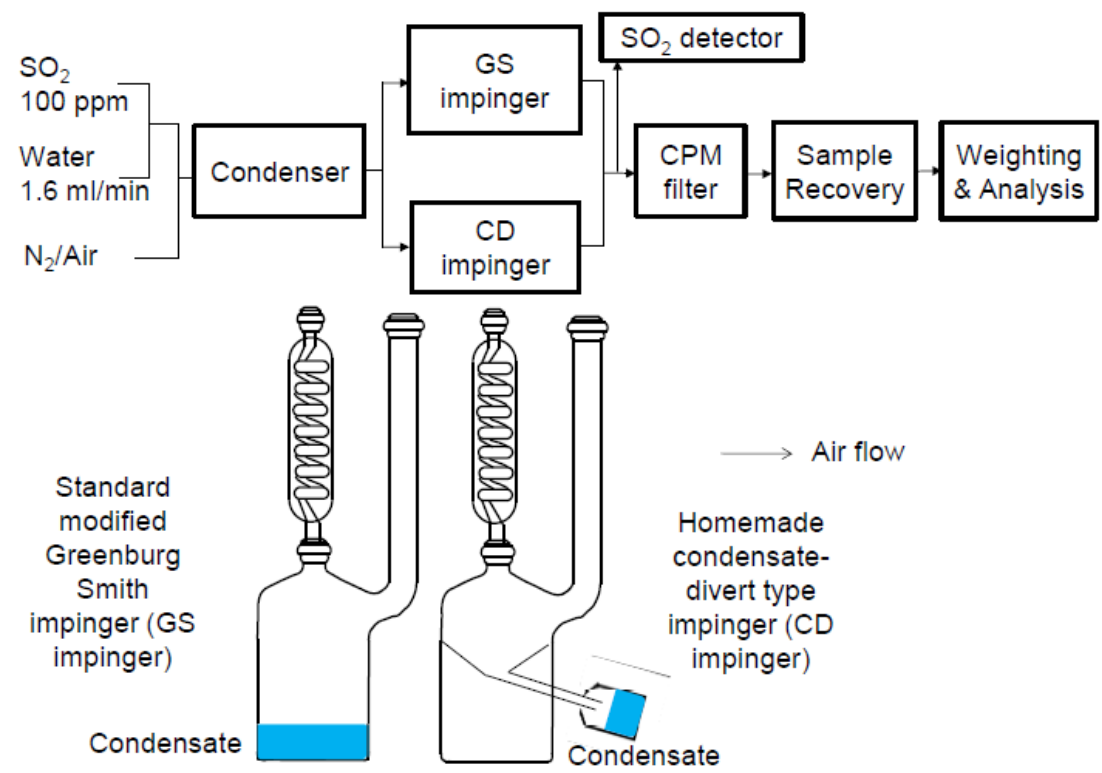

Fig. 1. Schematic of the CPM measurement system.

Table 1. List of operating parameters.

\begin{tabular}{llll}
\hline Parameter & Unit & Abbreviation & Range \\
\hline $\mathrm{SO}_{2}$ conc. & $\mathrm{ppm}$ & - & 100 \\
Adsorbent (water) & $\mathrm{mL}$ & - & $100-300$ \\
Carrier gas & - & - & Air, $\mathrm{N}_{2}$ \\
Flow rate & $\mathrm{L} \mathrm{min}^{-1}$ & $\mathrm{Q}_{\mathrm{s}}$ & 10.6 \\
UHP N2 purging rate & $\mathrm{L} \mathrm{min}^{-1}$ & $\mathrm{Q}_{\mathrm{n}}$ & 14 \\
Residence time & $\mathrm{h}$ & $\mathrm{T}$ & $0.083-72$ \\
Impinger type & - & - & Homemade condensate-diverting (CD) impinger, \\
& & & standard modified Greenburg-Smith (GS) impinger \\
Forced ventilation chamber purging rate & $\mathrm{L} \mathrm{min}^{-1}$ & $\mathrm{Q}_{\mathrm{p}}$ & 16.1 \\
Distance from outlet to liquid surface & $\mathrm{cm}$ & $\mathrm{h}$ & $2-11$ \\
\hline
\end{tabular}

$\mathrm{CH}$ Technologies, Westwood, NJ, USA) was used to generate particles of different sizes to determine the correlation between particle size and purging time.

A condensation nuclei counter (P-Trak 8525; TSI Inc., Shoreview, MN, USA) was used to test the CPM filter holder for leakage. The filter paper selected for CPM collection was polytetrafluoroethylene (PTFE) filter paper (GF-3TM; Apex Instruments) recommended by the original manufacturer, with a diameter of $82.3 \mathrm{~mm}$ and a testing flow rate of $10 \mathrm{~L} \mathrm{~min}{ }^{-1}$. The effect of static electricity on weighing results was evaluated using ${ }^{241} \mathrm{Am}$ (370 MBq; TSI Inc.) as a neutralizer, and the effects of different beaker sizes $(25,100,150$, and $250 \mathrm{~mL}$ ) were also investigated. The condition time was improved using a forced ventilation chamber (Fig. 2), with the following dimensions: length of $30 \mathrm{~cm}$, width of $15 \mathrm{~cm}$, and height of $30 \mathrm{~cm}$. The total flow rate at the inlet was $32.2 \mathrm{~L} \mathrm{~min}^{-1}$. The flow was divided and exited the system from two outlets, each with a flow rate of $16.1 \mathrm{~L} \mathrm{~min}^{-1}$. The distance from the outlet to the surface of the sample was varied $(2-11 \mathrm{~cm})$ to determine the optimal drying time.

\section{RESULTS AND DISCUSSION}

\subsection{Verification of Positive Bias}

\subsubsection{Absorption and desorption curve of water for $\mathrm{SO}_{2}$}

To detect positive bias in the measurement of $\mathrm{CPM}$ due to $\mathrm{SO}_{2}, 100 \mathrm{~mL}$ of pure water was placed in the GS impinger, and $100 \mathrm{ppm}$ of $\mathrm{SO}_{2}$ was aerated in water at a flow rate of $10.6 \mathrm{~L} \mathrm{~min}^{-1}$. 


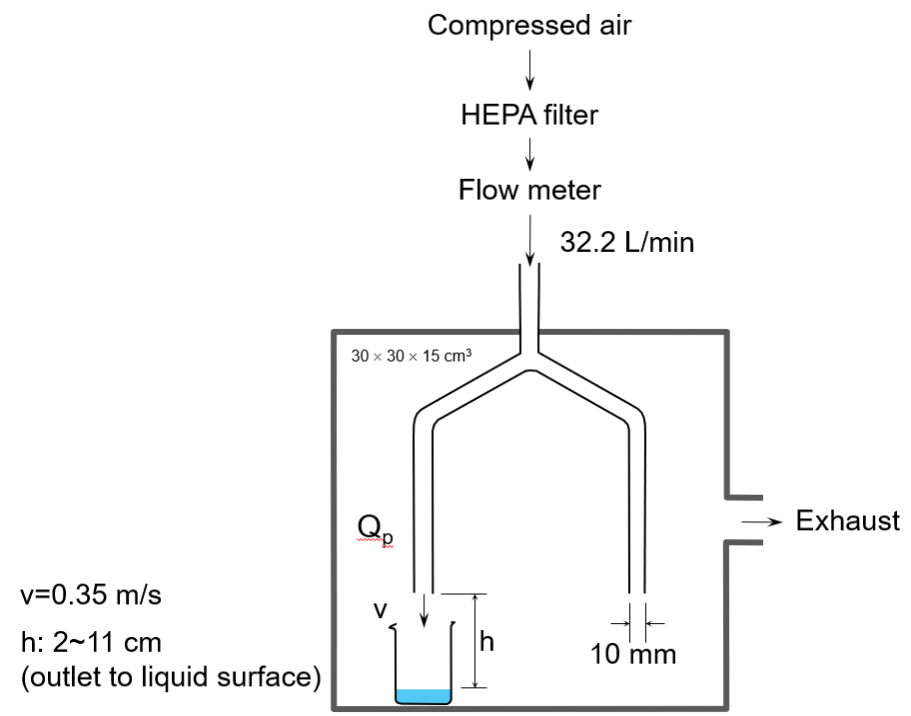

Fig. 2. Schematic of the forced ventilation chamber setup.

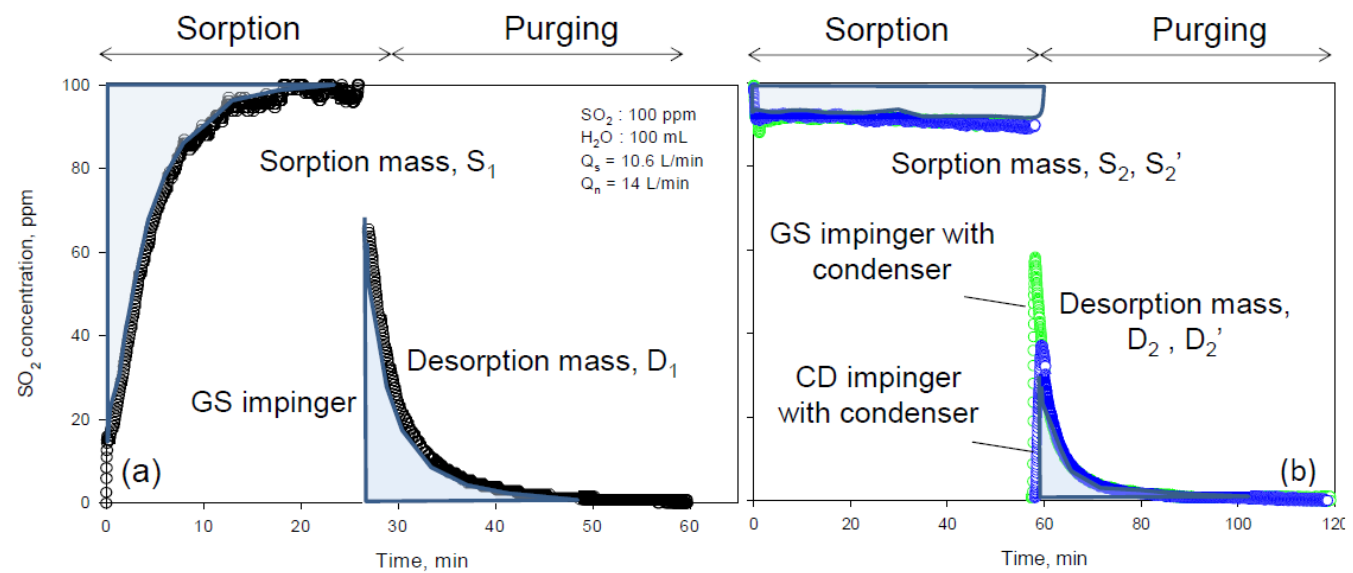

Fig. 3. Sorption and desorption of $\mathrm{SO}_{2}$ in water.

The results are shown in Fig. 3(a). The absorption curve of water for $\mathrm{SO}_{2}$ revealed that at the beginning of the experiment, $\mathrm{SO}_{2}$ could be measured at the outlet of the impinger, and it reached $100 \%$ breakthrough in approximately $20 \mathrm{~min}$. The area above the curve is the total amount of $\mathrm{SO}_{2}$ absorbed by water-approximately $14.9 \mathrm{mg}\left(\mathrm{S}_{1}\right)$. Nitrogen purging was directly and immediately applied to the impinger when breakthrough occurred. After $25 \mathrm{~min}, \mathrm{SO}_{2}$ could not be measured. The area under the curve was the total amount of $\mathrm{SO}_{2}$ that could be purgedapproximately $9.82 \mathrm{mg}\left(\mathrm{D}_{1}\right)$. It can be inferred that the total amount of $\mathrm{SO}_{2}$ remaining in the water was $5.08 \mathrm{mg}$-approximately $33.58 \%$. The forced aeration step used here is different from Method 202 to acquire the greatest amount of possible positive bias resulting from that amount of $\mathrm{SO}_{2}$ absorbed in the water.

To simulate the contact time between water and $\mathrm{SO}_{2}$ during field sampling measurement, water and $\mathrm{SO}_{2}$ were injected into the Graham condenser and impinger at the same time. According to the previous result, the contact time of water and $\mathrm{SO}_{2}$ is the key point of positive bias. In this experiment, a funnel was placed in the impinger to divert the condensate outside the impinger and thereby reduce the time of contact between water and $\mathrm{SO}_{2}$ in the flue gas, thereby reducing the amount of artifacts. The results are shown in Fig. 3(b). In terms of the absorption curve, the breakthrough curves in Figs. 3(a) and 3(b) are significantly different because under nonaeration conditions, freshwater was injected continuously into the condenser, thus maintaining contact with $\mathrm{SO}_{2}$. Therefore, the $\mathrm{SO}_{2}$ concentration measured at the impinger outlet remained stable, and approximately $10 \%$ of the $\mathrm{SO}_{2}$ could be absorbed. However, the difference 
in the mass of $\mathrm{SO}_{2}$ absorbed in the water between GS impinger (14.99 $\left.\pm 2.9 \mathrm{mg}\left[\mathrm{S}_{2}\right]\right)$ and $\mathrm{CD}$ impinger (15.94 $\left.\pm 3.56 \mathrm{mg}\left[\mathrm{S}_{2}{ }^{\prime}\right]\right)$ is negligible. Nitrogen purging was performed after the $\mathrm{SO}_{2}$ concentration reached $100 \%$ breakthrough. The mass of $\mathrm{SO}_{2}$ purged from the water by the GS impinger and $C D$ impinger was $8.34 \pm 1.16 \mathrm{mg}\left(D_{2}\right)$ and $9.86 \pm 2.19 \mathrm{mg}\left(D_{2}{ }^{\prime}\right)$, respectively, and the residual $\mathrm{SO}_{2}$ mass in the water was $5.30 \pm 2.61 \mathrm{mg}$ and $6.59 \pm 2.59 \mathrm{mg}$, respectively. The residual percent was $35.29 \pm 10.75 \%$ and $36.89 \pm 11.46 \%$, respectively. The amount of $\mathrm{SO}_{2}$ artifacts removed through purging also did not differ significantly between the two impingers. A possible reason for this finding is that $\mathrm{SO}_{2}$ absorption in the water occurred when water was passing through the condenser, even if only for $10 \mathrm{~s}$. Thus, when the gas and liquid were separated by the funnel in the $C D$ impinger, the expected results could not be achieved. Future efforts should be made to reduce the time and area of contact between water and $\mathrm{SO}_{2}$ to minimize the formation of artifacts.

\subsubsection{Effects of sampling time on positive bias}

During field sampling, nitrogen purging was not performed immediately after the CPM collection step. The absorption of $\mathrm{SO}_{2}$ in the water may persist until the completion of other sampling steps. Therefore, the total duration of sampling (aeration) and waiting was the main factor affecting the positive bias caused by $\mathrm{SO}_{2}$. The residence time was defined as the sum of sampling and wait times. A 3-h experiment was designed to simulate the residence time before the nitrogen purging of field sampling. In one set, aeration lasted for $3 \mathrm{~h}$ with no wait time and the $\mathrm{SO}_{2}$ recovery ratio was $40.2 \%$, whereas in the other set, aeration lasted for $0.5 \mathrm{~h}$ with a $2.5-\mathrm{h}$ wait time and the $\mathrm{SO}_{2}$ recovery ratio was $41.7 \%$; the difference was not significant. Therefore, the factor affecting the $\mathrm{SO}_{2}$ recovery ratio was the residence time: Neither sampling time nor wait time alone affected the recovery ratio. In general, the shorter the duration of field sampling, the more $\mathrm{SO}_{2}$ could be removed through nitrogen purging. At the residence times of $5,27,32$, $150,566,2880$, and $4320 \mathrm{~min}$, the recovery efficiency of $\mathrm{SO}_{2}$ was $99.5 \%, 66.4 \%, 61.7 \%, 45.5 \%$, $39.8 \%, 37.7 \%$, and $38.0 \%$, respectively. The reason for this is that the longer the residence time, the more $\mathrm{SO}_{2}$ dissolves in the water and forms $\mathrm{SO}_{3}{ }^{2-}$ and $\mathrm{SO}_{4}{ }^{2-}$, leaving less $\mathrm{SO}_{2}$ to be purged and reducing the amount of time required for nitrogen purging.

\subsubsection{Effects of oxygen content and water content on positive bias}

The formation of $\mathrm{SO}_{3}{ }^{2-}$ and $\mathrm{SO}_{4}{ }^{2-}$ from $\mathrm{SO}_{2}$ requires oxygen. Thus, oxygen concentration is also a factor causing CPM positive bias. A fixed time (150 $\mathrm{min}$ ) was set for two experiments that used air and nitrogen as a carrier gas; the $\mathrm{SO}_{2}$ recovery ratio was $45.5 \%$ and $58.9 \%$, respectively. When air was used for dilution, the oxygen in it allowed $\mathrm{SO}_{2}$ to easily oxidize and form sulfuric acid, thus increasing the positive bias of the $\mathrm{SO}_{2}$. In other words, in actual sampling, the higher the oxygen content in the flue gas, the easier it is to overestimate the CPM results.

The stack moisture content and the sampling time affect the moisture content in the impinger. The positive bias caused by $100 \mathrm{ppm}$ of $\mathrm{SO}_{2}$ at different water quantities $(100,200$, and $300 \mathrm{~mL})$ is shown in Fig. 4(a). The amount of $\mathrm{SO}_{2}$ dissolved, the amount of $\mathrm{SO}_{2}$ that nitrogen has purged, and the residual amount of $\mathrm{SO}_{2}$ all increased as the amount of water in the impinger increased, and a linear correlation was observed. Irrespective of the water volume, the ratio of the amount of $\mathrm{SO}_{2}$ dissolved to the amount of $\mathrm{SO}_{2}$ that nitrogen has purged was approximately $65 \%$. Thus, the moisture content of the flue gas may lead to overestimation of the sampling results, and when the amount of water increases, although the proportion of $\mathrm{SO}_{2}$ purged and the amount of residue are almost identical, the mass of the residue is higher than that of the purged $\mathrm{SO}_{2}$. The more water in the stack, the higher the residual $\mathrm{SO}_{2}$ mass in the water, and the ratio of overestimation is directly proportional to the amount of water. The results are shown in Fig. 4(b).

\subsubsection{Beaker weighing bias}

Weighing bias due to static electricity should be avoided. This study explored the effect of electrostatic interaction on beaker weighing for different beaker sizes (Fig. 5). Larger beakers carry more static electricity and are thus more influenced by static electricity during weighing. It may be speculated that frictional charging occurs when the hand touches the beaker and the electric charge of the hand is transferred to the beaker. Larger beakers have more surface area 


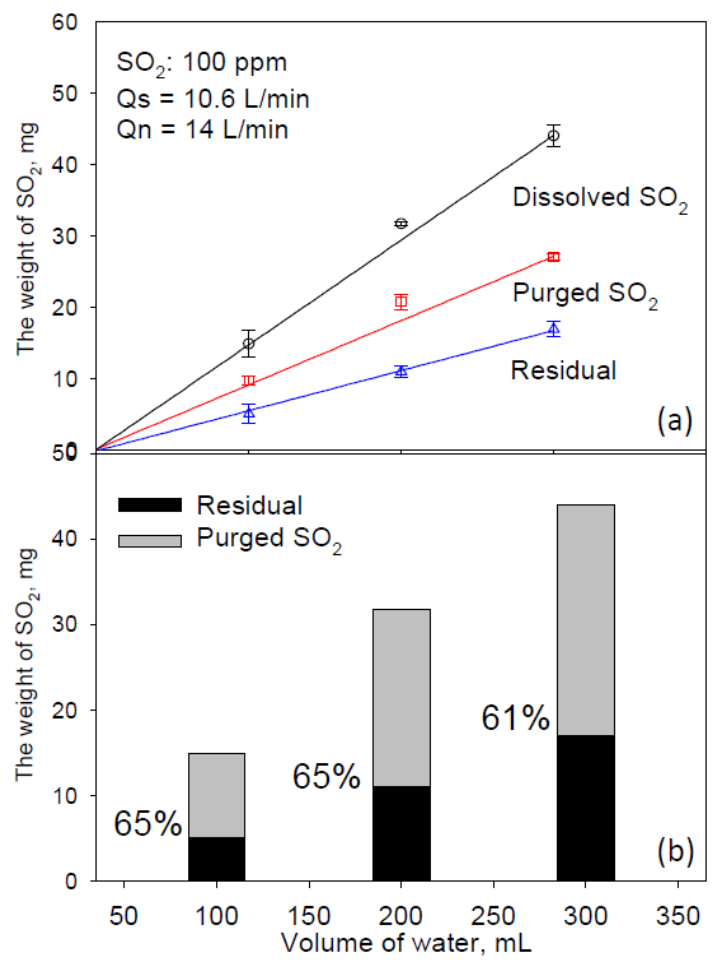

Fig. 4. Effect of water volume on $\mathrm{SO}_{2}$ recovery and residual amount.

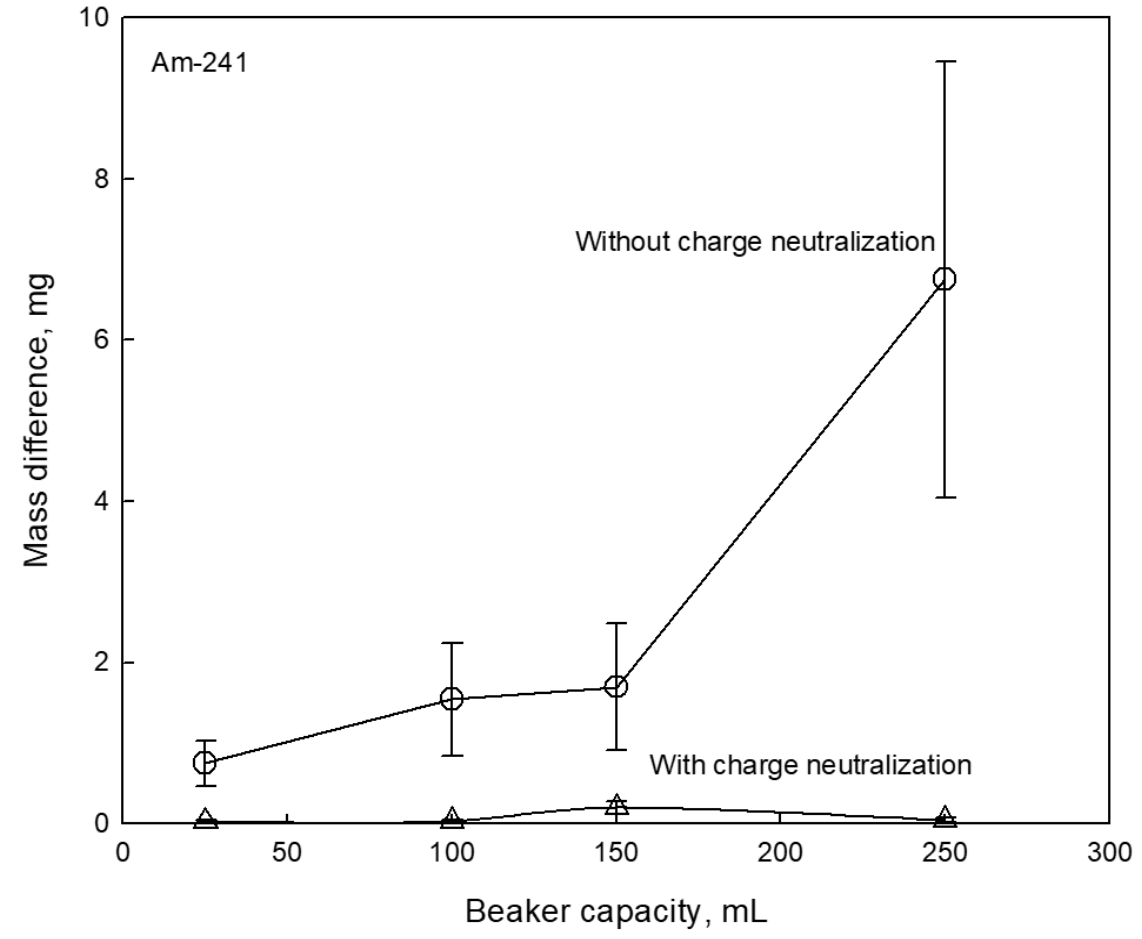

Fig. 5. Effect of electrostatic charge on beaker weighing.

to carry charges. For a $100-\mathrm{mL}$ beaker, the bias caused by nonstatic neutralization can reach $1.8 \mathrm{mg}$. If the sampling volume is $1 \mathrm{Nm}^{3}$, then the bias caused by weight concentration is $1.8 \mathrm{mg} \mathrm{Nm}^{-3}$. The experiment results indicate that when the weighing container is a poor conductor (e.g., glassware), thorough performance of the electrostatic neutralization step is necessary. 


\subsection{Verification of Negative Bias}

\subsubsection{Effect of nitrogen purging on filter paper collection samples}

Method 202 involves the use of the nitrogen purging procedure to reduce the positive bias of $\mathrm{SO}_{2}$ in flue gas, but the CPM collected on the filter paper behind the impinger may cause weight loss during nitrogen purging. In the experiment, glycerol and DEHS were used as CPM with different vapor pressures. The weight loss after nitrogen purging is shown in Fig. 6 . The original weights of glycerol and DEHS on the filter paper were 8 and $5.5 \mathrm{mg}$, respectively. The weight of DEHS did not change after tests with different purging times, but that of glycerol decreased with the increase in purging time. Three particle sizes (1.17, 5.05, and $1178 \mu \mathrm{m})$ were employed in this study. Particles with the size of $1178 \mu \mathrm{m}$ were administered onto the filter paper by using a pipette. The data indicated that the particles with a smaller diameter had larger surfaces and lost weight more easily for the same mass. If nitrogen purging according to this method lasted for at least $1 \mathrm{~h}$, then the percentage of weight loss of the glycerol particles would be between $25 \%$ and $50 \%$ for particle sizes of 5.05 and $1.17 \mu \mathrm{m}$, respectively. However, no significant reduction was observed in the mass of particles with a diameter of $1178 \mu \mathrm{m}$ because the coverage area on the filter paper was smaller than that for the other two particle sizes ( 1.17 and $5.05 \mu \mathrm{m})$. The volatility of CPM is directly proportional to the vapor pressure at the same temperature. Because glycerol has a saturated vapor pressure $\left(1.68 \times 10^{-4} \mathrm{mmHg}\right.$ at $\left.25^{\circ} \mathrm{C}\right)$ that is lower than that of DEHS $\left(10^{-7}\right.$ $\mathrm{mmHg}$ at $25^{\circ} \mathrm{C}$ ), it is the more volatile of the two. Moreover, the weight of substances with a vapor pressure of $<10^{-7} \mathrm{mmHg}$ was unaffected by nitrogen purging. This may be related to the surface area or coverage rate of glycerol on the filter paper.
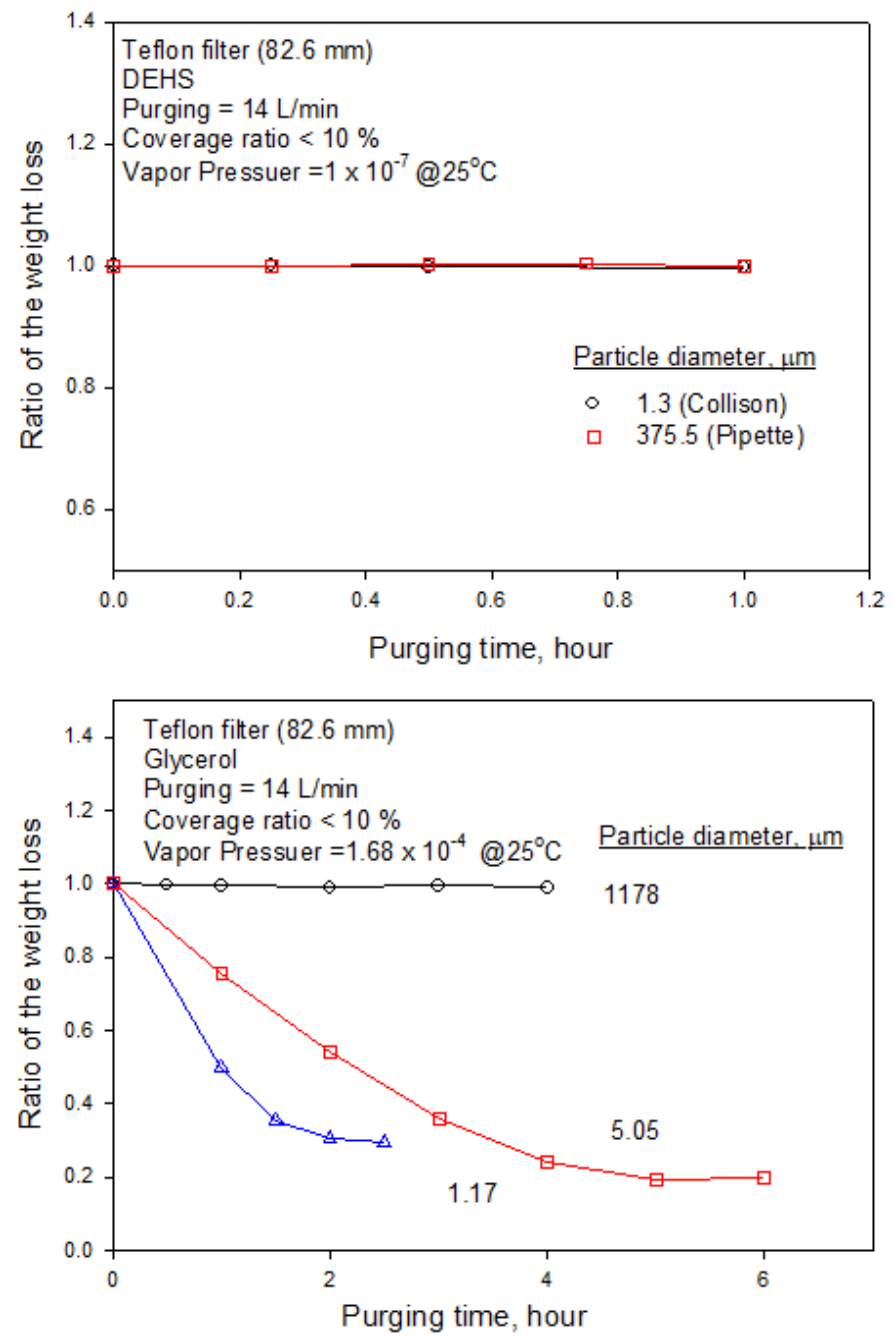

Fig. 6. Effect of purging time on the weight loss for different volumes of glycerol and DEHS. 
In the experiment, filter paper was loaded with particles of different weights but the same size to evaluate the effect of mass loading. For glycerol particles with a diameter of $1.17 \mu \mathrm{m}$, after $2 \mathrm{~h}$ of nitrogen purging with different coverage rates $(80 \%, 50 \%, 40 \%$, and $10 \%)$, the weight loss of glycerol particles was $16 \%, 30 \%, 34 \%$, and $65 \%$, respectively. A lower coverage rate resulted in fewer particles on the filter paper. The rate of weight loss of the particles on the filter paper decreased faster with nitrogen purging. The larger the particle numbers, the higher the probability of deposition on the same location; consequently, only the amount of surface CPM decreased with nitrogen purging, and the relative rate of particle weight reduction also decreased. Therefore, the proportion of underestimation caused by nitrogen purging increases at low concentration of CPM. Replacement of the filter paper before nitrogen purging may prevent weight loss.

\subsubsection{Effect of solvent volume on recovery efficiency}

Rinsing is required for recovery of the CPM adhered to the impinger inner surface. The recovery efficiency of DEHS when different rinse volumes of hexane were used is displayed in Fig. 7. When the DEHS mass in the impinger was $0.45 \mathrm{~g}$, the addition of $35 \mathrm{~mL}$ of hexane to the impinger for rinsing achieved $95 \%$ recovery efficiency, but the addition of $50 \mathrm{~mL}$ of hexane only increased recovery efficiency by an additional $1 \%$, that is, to $96 \%$. Increasing the eluent volume can increase the recovery efficiency, but it also increases the drying time later during the analysis procedure.

After the extraction step in the analysis procedure of Method 202 was performed, the inorganic and organic fractions of the solution were required to be evaporated to approximately $10 \mathrm{~mL}$ and then transferred to a 50-mL pre-tared weighing tin. During transfer, the CPM solution may leave some residue in the previous beaker, which would introduce bias in the results. The results are presented in Fig. 8. The residual ratio remaining in the beaker increased as the beaker size and CPM solution volume decreased. For example, with a $150-\mathrm{mL}$ beaker, when the volume of the CPM solution after drying was 5,10 , or $20 \mathrm{~mL}$, the residual amount in the beaker after the solution was transferred to a tin $(5.72 \%, 2.22 \%$, and $0.91 \%)$ was progressively smaller because the solute was nonvolatile. Some solutions adhere to the inner surface of the beaker during transfer; hence, the beaker size also plays a vital role. Transferring smaller volumes results in greater underestimation because of the higher residual and transfer volume percentages. Smaller amounts of solution transferred also indicate higher CPM concentrations because the solvent was volatile. Fig. 8 reveals that the residual ratio was the highest when the volume of residue in the beaker was $5 \mathrm{~mL}$, regardless of the beaker capacity, leading to an underestimation of approximately 2-6\%. In Method 202, performing the transfer step when the beaker is holding $10 \mathrm{~mL}$ of content would lead to a 1-3\% underestimation. Therefore, if the total cumulative weight of the extract and the beaker does not exceed the measurable range, then the extract transfer step should not be performed or the mass of the residue in the beaker should be added to the result after transfer to avoid underestimation.

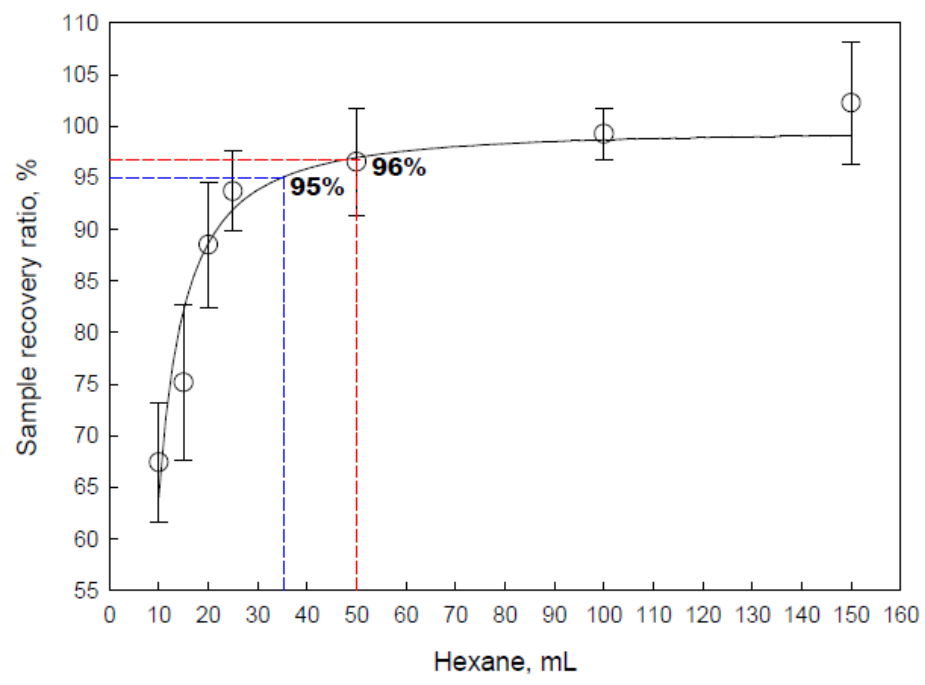

Fig. 7. Effect of the amount of hexane on the sample recovery ratio. 


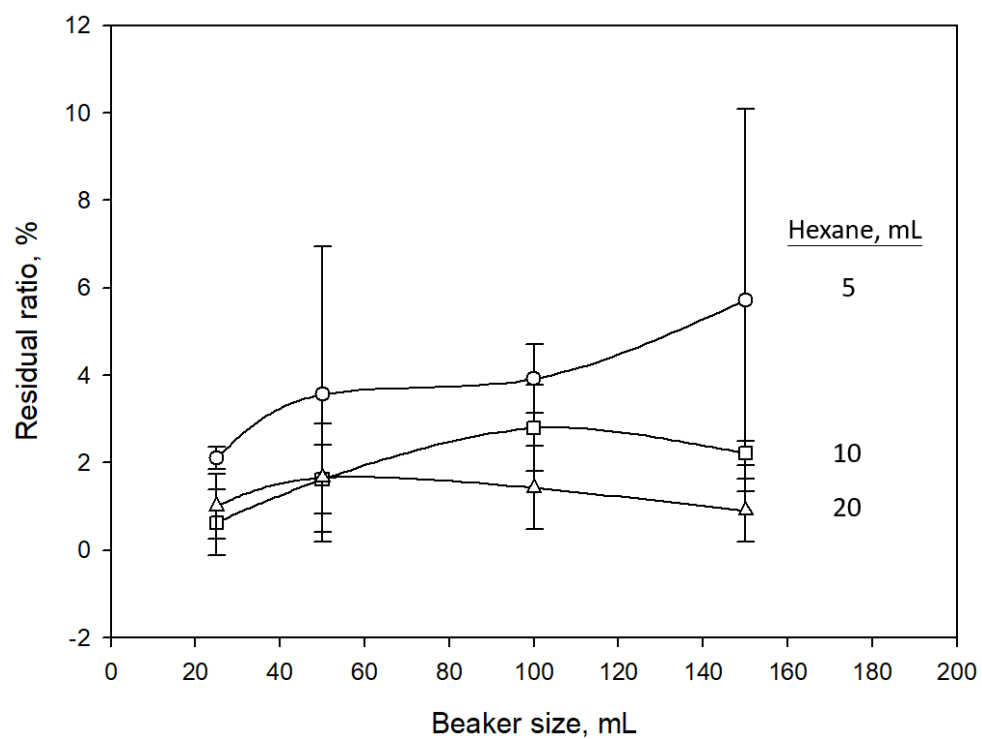

Fig. 8. Effect of the amount of hexane on the residual ratio of beakers with different capacities.

\subsubsection{Filter holder leakage}

The filter paper behind the impinger was used to capture the CPM escaping from the impinger, but the particles passed through the gap between the filter paper and the filter paper holder, resulting in underestimation of the total mass. The results are shown in Fig. 9. The percentage of particle loss due to this leakage was $4 \%$. After the gap was filled with a gasket, the particle loss was $<0.06 \%$. Therefore, attention must be paid to the tightness of the filter paper and the holder in use, and if necessary, an O-ring or gasket must be inserted to increase the air tightness.

\subsection{Improvement of Sample Drying Time}

The analysis procedure requires evaporation of the organic extract until it is dry at room temperature in a chemical hood, but it takes several days to fully dry, whereas an inorganic extract must be baked on a hot plate or in an oven at $105^{\circ} \mathrm{C}$. In this study, a forced ventilation chamber was designed to reduce the drying time of the residue; the results are discussed separately for the organic and inorganic extracts.

\subsubsection{Organic extract}

DEHS $(0.22 \mathrm{~g})$ and hexane $(100 \mathrm{~mL})$ as the solute and solvent, respectively, were added to a beaker $(4.7 \mathrm{~cm}$ in diameter, volume of $100 \mathrm{~mL}$ ), which was placed in a chemical hood following completion of the procedures for Method 202. Fig. 10 compares the time required for full implementation of the method with that required for using a forced ventilation chamber. It took approximately $100 \mathrm{~h}$ to dry the organic extract in the chemical hood. In the forced ventilation chamber, however, when the distance from the air outlet to the liquid surface was $2 \mathrm{~cm}$, it took only $1.5 \mathrm{~h}$ for the sample to dry; at a distance of $5 \mathrm{~cm}$, it took only $1.75 \mathrm{~h}$; and at a distance of $11 \mathrm{~cm}$, it took $2.5 \mathrm{~h}$. These results indicate that the distance should be as short as possible to reduce the drying time. However, disturbance of the solution surface should be avoided at short distances. The results of sample drying with a forced ventilation chamber are consistent with those of sample drying with a chemical hood, reaching $98.5 \%$ recovery efficiency. Therefore, the organic fraction can be dried using the forced ventilation chamber, thus effectively reducing the drying time.

\subsubsection{Inorganic extract}

During the experiment on the inorganic extract, $0.22 \mathrm{~g}$ of $\mathrm{NaCl}$ and $100 \mathrm{~mL}$ of water were placed in two beakers that had been weighed. One beaker was placed in an oven at a temperature of $105^{\circ} \mathrm{C}$, and the other was placed in a forced ventilation chamber; it took 2 and $5 \mathrm{~h}$, respectively, for the samples to dry. The drying time was not reduced in the ventilation 


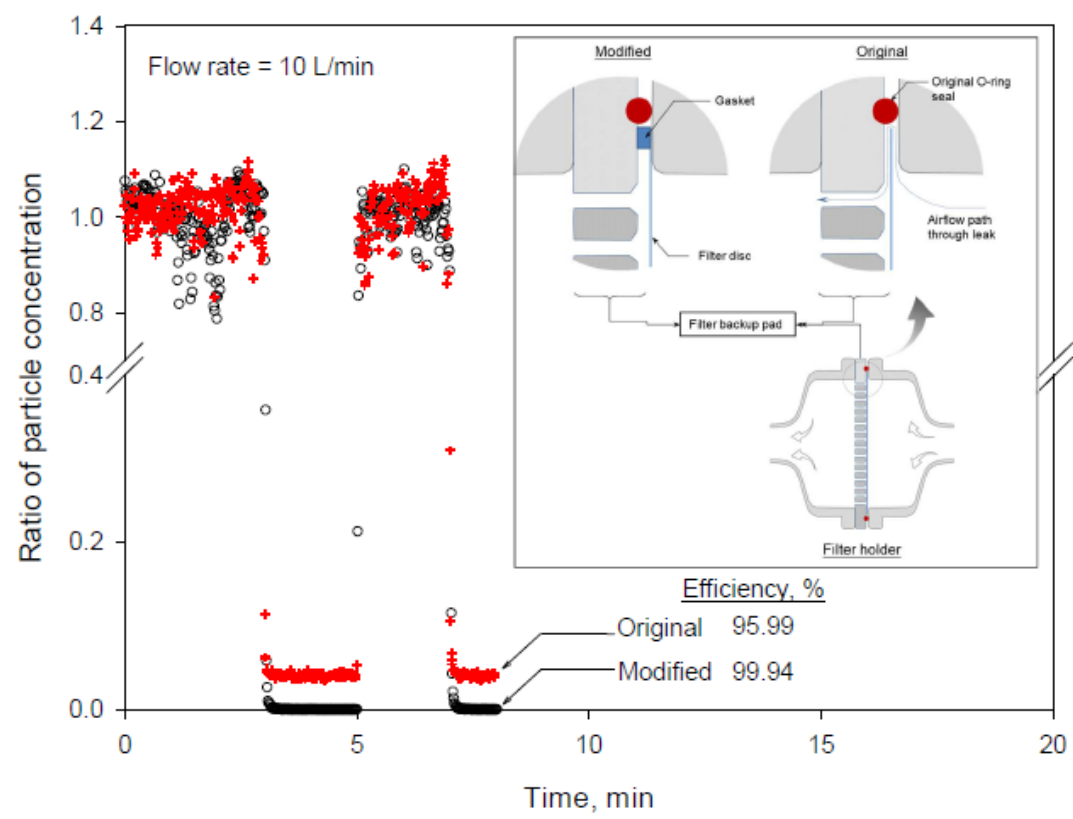

Fig. 9. Effect of O-ring leakage on the recovery efficiency of the CPM filter.

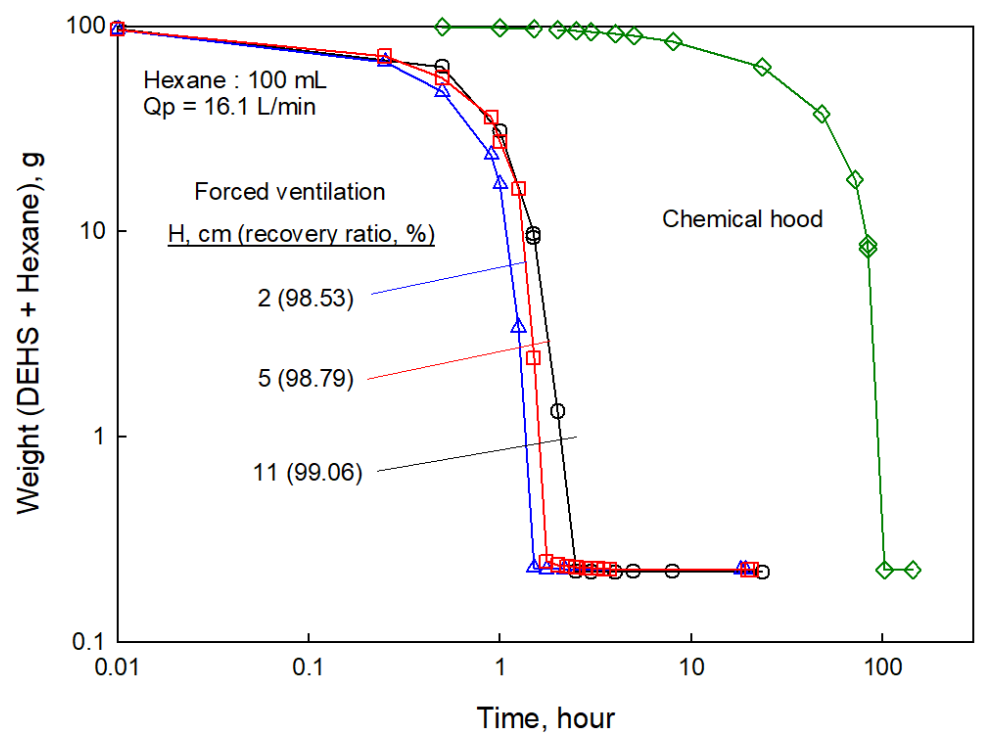

Fig. 10. Effect of conditioning on the weight of the organic sample.

chamber for inorganic samples. Weighing the beaker after drying, whether in an oven or a forced ventilation chamber, led to $>99 \%$ recovery of the extract.

In the experiment for improving the conditioning time of the sample, the drying time could be effectively reduced using a forced ventilation chamber because the gas exchange rate could be improved. Nevertheless, water condensation may develop on the beaker's outer surface because of temperature reduction due to evaporation, and it is necessary to remove this condensation before weighing to avoid overestimation of CPM. The drying time for organic samples, but not for inorganic samples, can be reduced using a forced ventilation chamber.

\section{CONCLUSIONS AND RECOMMENDATIONS}

This study evaluated the sources of positive and negative measurement biases in Method 202. The main findings are as follows: 
1) Artifacts due to the water's absorption of the $\mathrm{SO}_{2}$, which contribute to positive bias, cannot be avoided as long as condensation occurs.

2) Reducing the duration of contact between the $\mathrm{SO}_{2}$ and the water can decrease the positive bias.

3) Replacing the filter paper prior to purging the CPM sample with nitrogen can prevent particle weight loss via evaporation, but it also increases the complexity of the sample and hence the analysis. Lengthening the purging time does not increase the recovery efficiency of the dissolved $\mathrm{SO}_{2}$ and may cause significant underestimation.

4) The gap between the filter paper and its holder can cause CPM loss; thus, an O-ring or gasket should be inserted to enhance the air tightness.

5) To reduce the amount of residue (to $0.09 \%$ ), the aqueous-phase fraction should be evaporated in the beaker till its volume is no more than $20 \mathrm{~mL}$. Alternatively, the residual CPM can be weighed in the beaker both before and after transferring the latter's contents.

6) When the weighing container is a poor conductor of electricity (such as glassware), it should be electrostatically neutralized prior to being weighed.

7) Using forced ventilation can greatly reduce the drying time of the organic (but not inorganic) fraction, which decreased from 100 to $2.5 \mathrm{~h}$ in our experiment.

\section{ACKNOWLEDGMENTS}

The authors would like to thank the Environmental Protection Administration, Executive Yuan, ROC (Taiwan), for financially supporting this study.

\section{REFERENCES}

Apte, J.S., Marshall, J.D., Cohen, A.J., Brauer, M. (2015). Addressing global mortality from ambient PM2.5. Environ. Sci. Technol. 49, 8057-8066. https://doi.org/10.1021/acs.est.5b01236

Corio, L.A., Sherwell, J. (2000). In-stack condensible particulate matter measurements and issues. J. Air Waste Manage. Assoc. 50, 207-218. https://doi.org/10.1080/10473289.2000.10464002

DeWees, W.G., Steinsberger, S.C., Plummer, G.M., Lay, L.T., McAlister, G.D., Shigehara, R.T. (1989). Laboratory and field evaluation of the EPA method 5 impinger catch for measuring condensable matter from stationary source, in Proceedings of the 1989 EPA/A\&WMA International Symposium on Measurement of Toxic and related Air Pollutants, U.S. Environmental Protection Agency, Research Triangle Park, North Carolina, Pittsburg, PA.

England, G.C., Zielinska, B., Loos, K., Crane, I., Ritter, K. (2000). Characterizing PM2.5 emission profiles for stationary sources: Comparison of traditional and dilution sampling techniques. Fuel Processing Technol. 65-66, 177-188. https://doi.org/10.1016/S0378-3820(99)00085-5

Richards, J., Holder, T. and Goshaw, D. (2005). Optimized method 202 sampling train to minimize the biases associated with method 202 measurement of condensable particulate matter emissions, in Air \& Waste Management Association Hazardous Waste Combustion Specialty Conference St. Louis, Missouri.

Karthik, K.R.G., Baikie, T., Mohan Dass, E.T., Huang, Y.Z., Guet, C. (2017). Understanding the Southeast Asian haze. Environ. Res. Lett. 12, 084018. https://doi.org/10.1088/1748-9326/aa7 $5 d 5$

Li, J., Qi, Z., Li, M., Wu, D., Zhou, C., Lu, S., Yan, J., Li, X. (2017). Physical and chemical characteristics of condensable particulate matter from an ultralow-emission coal-fired power plant. Energy Fuels 31, 1778-1785. https://doi.org/10.1021/acs.energyfuels.6b02919

Li, X., Zhou, C., Li, J., Lu, S., Yan, J. (2019). Distribution and emission characteristics of filterable and condensable particulate matter before and after a low-low temperature electrostatic precipitator. Environ. Sci. Pollut. Res. Int. 26, 12798-12806. https://doi.org/10.1007/s11356019-04570-y

Miller, B. (2015). 1 - Introduction, in: Miller, B. (Ed.), Fossil fuel emissions control technologies, Butterworth-Heinemann, pp. 1-45. https://doi.org/10.1016/B978-0-12-801566-7.00001-4

Pei, B. (2015). Determination and emission of condensable particulate matter from coal-fired 
power plants. Huan Jing ke Xue 36, 1544-1559.

Qi, Z., Li, J., Wu, D., Xie, W., Li, X., Liu, C. (2017). Particulate matter emission characteristics and removal efficiencies of a low-low temperature electrostatic precipitator. Energy Fuels 31, 1741-1746. https://doi.org/10.1021/acs.energyfuels.6b02692

Ramanathan, V., Ramana, M. V., Roberts, G., Kim, D., Corrigan, C., Chung, C., Winker, D. (2007). Warming trends in Asia amplified by brown cloud solar absorption. Nature 448, 575-578. https://doi.org/10.1038/nature06019

United States Environmental Protection Agency (U.S. EPA) (2016). Method 202-dry impinger method for determining condensable particulate emission from stationary sources. https://www.epa.gov/emc/method-202-condensable-particulate-matter

Wang, G., Deng, J., Ma, Z., Hao, J., Jiang, J. (2018). Characteristics of filterable and condensable particulate matter emitted from two waste incineration power plants in China. Sci. Total Environ. 639, 695-704. https://doi.org/10.1016/j.scitotenv.2018.05.105

Wang, G., Deng, J., Zhang, Y., Li, Y., Ma, Z., Hao, J., Jiang, J. (2020). Evaluating airborne condensable particulate matter measurement methods in typical stationary sources in China. Environ. Sci. Technol. 54, 1363-1371. https://doi.org/10.1021/acs.est.9b05282

Wang, Y., Cheng, K., Tian, H.Z., Yi, P., Xue, Z.G. (2016). Emission characteristics and control prospects of primary $\mathrm{PM}_{2.5}$ from fossil fuel power plants in China. Aerosol Air Qual. Res. 16, 3290-3301. https://doi.org/10.4209/aaqr.2016.07.0324

Xie, Y., Dai, H., Dong, H., Hanaoka, T., Masui, T. (2016). Economic impacts from PM2.5 pollutionrelated health effects in China: A provincial-level analysis. Environ. Sci. Technol. 50, 4836-4843. https://doi.org/10.1021/acs.est.5b05576

Yang, H.H., Arafath, S.M., Lee, K.T., Hsieh, Y.S., Han, Y.T. (2018a). Chemical characteristics of filterable and condensable $\mathrm{PM}_{2.5}$ emissions from industrial boilers with five different fuels. Fuel 232, 415-422. https://doi.org/10.1016/j.fuel.2018.05.080

Yang, H.H., Arafath, S.M., Wang, Y.F., Wu, J.Y., Lee, K.T., Hsieh, Y.S. (2018b). Comparison of coaland oil-fired boilers through the investigation of filterable and condensable $\mathrm{PM}_{2.5}$ sample analysis. Energy Fuels 32, 2993-3002. https://doi.org/10.1021/acs.energyfuels.7b03541

Yang, H.H., Gupta, S.K., Dhital, N.B., Lee, K.T., Hsieh, Y.S., Huang, S.C. (2019). Establishment of indicatory metals for filterable and condensable $\mathrm{PM}_{2.5}$ emitted from important stationary emission sources. Energy Fuels 33, 10878-10887. https://doi.org/10.1021/acs.energyfuels.9b 02889

Yang, H.H., Lee, K.T., Hsieh, Y.S., Luo, S.W., Huang, R.J. (2015). Emission characteristics and chemical composition of both filterable and condensable fine particulate from steel plants. Aerosol Air Qual. Res. 15, 1672-1680. https://doi.org/10.4209/aaqr.2015.06.0398

Yang, H.H., Lee, K.T., Hsieh, Y.S., Luo, S.W., Li, M.S. (2014). Filterable and condensable fine particulate emissions from stationary sources. Aerosol Air Qual. Res. 14, 2010-2016. https://doi.org/10.4209/aaqr.2014.08.0178

Yang, Y., Hou, Q., Zhou, C., Liu, H., Wang, Y., Niu, T. (2008). Sand/dust storm processes in Northeast Asia and associated large-scale circulations. Atmos. Chem. Phys. 8, 25-33. https://doi.org/10.5194/acp-8-25-2008

Zheng, C., Hong, Y., Liu, S., Yang, Z., Chang, Q., Zhang, Y., Gao, X. (2018). Removal and emission characteristics of condensable particulate matter in an ultralow emission power plant. Energy Fuels 32, 10586-10594. https://doi.org/10.1021/acs.energyfuels.8b02464 